\title{
Alat Pendeteksi Kebakaran Menggunakan SMS
}

\author{
Sindi Permata Sari ${ }^{1}$, Oriza Candra², dan Jhefri Asmi ${ }^{3}$ \\ 1,2,3 Universitas Negeri Padang \\ Jl. Prof Dr. Hamka Air Tawar, Padang, Indonesia \\ Shindypermata07@gmail.com¹, orizacandra@ft.unp.ac.id², jhefriasmi1998@gmail.com ${ }^{3}$
}

\begin{abstract}
Lately, there are frequent fires caused by human factors. Because we cannot predict the process of fire in advance. And the delay in knowing the occurrence of a fire is very fatal to the safety of human life and property. With advances in technology, we can overcome fires by making early fire detection devices. With the presence of temperature and smoke detectors, we can detect fires as early as possible and be delivered quickly via alarms and SMS gateways. The main component of this fire detector is the Arduino Uno. This Arduino uno acts as the brain of the fire detection device. This tool works based on the detection of the temperature condition by the DHT11 temperature sensor, which is when the temperature is above normal, an alert notification will be sent via the SMS gateway and so will the MQ2 smoke and the buzzer will sound as a warning alarm.
\end{abstract}

\section{Keywords-MikrokontrollerAtmega 328, ArduinoUno, SensorSuhuDHT11, Sensor Asap MQ2, Modul GSM, Buzzer}

\begin{abstract}
Abstrak - Akhir-akhir ini sering terjadi kebakaran yang disebabkan oleh factor manusia. Karna proses terjadinya kebakaran tidak dapat kita prediksi terlebih dahulu. Dan lambatnya mengetahui terjadinya kebakaran merupakan hal sangat fatal bagi keselamatan jiwa manusia dan harta benda. Dengan kemajuan teknologi kita bias mengatasi terjadinya kebakaran dengan membuat alat pendeteksi kebakaran dini.dengan adanya alat pendeteksi suhu dan asap kita dapat mengetahui kebakaran sedini mungkin dan disampaikan dengan cepat melalui alarmdan SMS gateway. Komponen utama dari alat pendeteksi kebakaran ini adalah arduino uno. Arduino uno ini berperan sebagai otak dari alat pendeteksi kebakaran. Alat ini bekerja berdasarkan deteksi keadaan suhu oleh sensor suhu DHT11 yaitu ketika suhu diatas normal pemberitahuan waspada akan terkirim melalui sms gateway dan begitu juga dengan asap MQ2 dan buzzer akan berbunyi sebagai alarm peringatan.
\end{abstract}

Kata kunci- MikrokontrollerAtmega328, ArduinoUno, SensorSuhuDHT11, Sensor Asap MQ2, Modul GSM, Buzzer

\section{Pendahuluan}

Kebakaran merupakan bencana yang dapat disebabkan oleh faktor manusia,faktor teknis maupun faktor alam yang tidak dapat diperkirakan kapan terjadinya. Kemajuan teknologi yang begitu pesat membuat kehidupan manusia menjadi lebih mudah dan praktis. Kemajuan teknologi tersebut salah satu diantaranya adalah teknologi mikrokontroler. Penggunaan mikrokontroler akhir-akhir ini sudah meluas kesegala bidang. Penggunaanya tidak haya pada bidang komputer saja, tetapi juga telah digunakan pada peralatan-peralatan elektronik lainnya, misalnya perangkat yang bisa kita lihat sehari-hari, seperti telepon seluler, televisi, mesin cuci bahkan sampai ke instrument ruang angkasa [1].

Karena banyaknya penduduk jumlah penduduk menyebabkan kondisi pemukiman menjadi padat, sehingga dapat menyebabkan kebakaran.kondisi kabel yang terpasang didalam rumah juga banyak mendapatkan kendala seperti kena air,lecet,digigit tikus,pemakaian yang berlebih dan pencurian arus itu dapat menyebabkan terjadinya kebakaran.

Kebakaran juga bisa disebabkan oleh tingginya suhu udara.Ketika suatu daerah mempunyai suhu yang tinggi, hal itu akan menpercepat terjadinya pengeringan bahan bakar dan memudahkan terjadinya kebakaran seperti pada saat musim kemarau panjang, pada saat kemarau suhu dipagi hari sangat rendah sekitar $20^{\circ} \mathrm{C}$ ditambah dengan kecepatan angin membuat apisehingga terkonsentrasi pada satu titik. Sementara siang hari dengan suhu $30^{\circ} \mathrm{C}-35^{\circ} \mathrm{C}$ sedangkan kadar air bahan bakar cukup rendah $(<30 \%)$ membuat proses pembakaran berlangsung cepat dan bentuk kebakarannya pun tidak satu titik, tapi berubah-ubah karena pengaruh angin [2].

Teknologi lainnya adalah media yang digunakan dalam suatu hubungan telekomunikasi jarak jauh sekarang ini tidak hanya menggunakan suatu kabel sebagai medianya, tetapi teknologi tanpa kabel yang biasa disebut dengan wireless sudah menjadi hal umum. Contoh teknologi tersebut adalah telepon seluler yang berkembang sangat pesat, dimana hampir setiap orang menggunakan telepon seluler dalam komunikasi.

Oleh karena itu telah dibuat alat pendeteksi kebakaran menggunakan sensor infrared dan sensor asap MQ-2 dengan output berupa SMS gateway yang akan terkirim saat adanya api atau asap yang terdeteksi. Alat yang digunakan untuk output SMS gateway yaitu GSM shield yang akan mengirimkan output SMS gateway yang terdeteksi api dan asap.tentunya GSM shield ini saling terintegrasi dengan sensor lainnya pada saat terjadi kebakaran. Dengan adanya alat pendeteksi kebakaran menggunakan mikrokontroler arduino uno kita sudah melakukan langkah awal yang penting dalam menyelamatkan diri sendiri dan orang lain jika bencana 
kebakaran terjadi pada suatu ruangan yang kemungkinan besar terjadi kebakaran.

\section{METODE}

Pada bab metode ini akan dibahas tentang perancangan hardware dan software dari alat.

\section{A. Blog Diagram}

Blok diagram sistem merupakan salah satu bagian yang begitu penting dalam merancang sebuah alat. Karena dapat memberitahu prinsip kerja dan hubungan komponen dalam rangkaian tersebut.

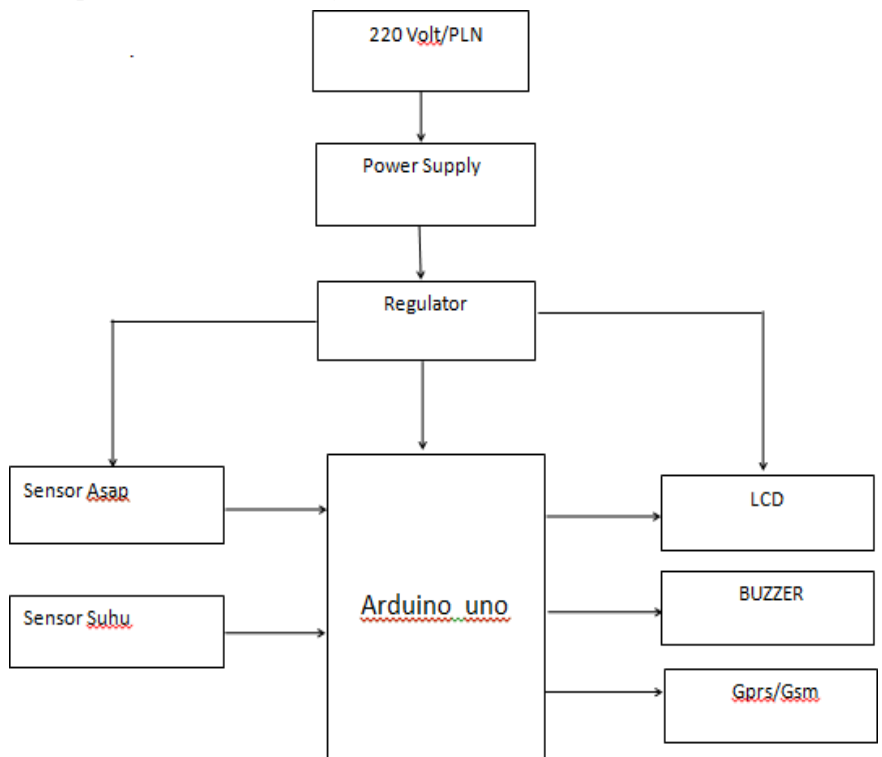

Gambar 1. Blok Diagram Alat Pendeteksi Kebakaran

Berdasarkan blog diagram pada gambar 1. Dapat dijelaskan komponen penyusunnya sebagai berikut:

1. Arduino Uno

Arduino merupakan pusat pengontrolan kerja alat, menerima data sensor dan mengolah data tersebut sesuai dengan keluaran yang diinginkan.

Arduino Nano adalah unit pengontrolan dan pemrosesan data pada system, sensor ldr disini berfungsi sebagai pemberi sinyal masukan atau input yang akan diteruskan dan diolah oleh Arduino nano, dan terakhir motor servo pada alat ini berfungsi sebagai penggerak [3][4][5].

2. Sensor asap MQ-2

Sensor asap MQ-2 berfungsi sebagai komponen inputan yang mampu mendeteksi asap yang ditimbulkan dari kebakaran pada ruang server [6].

3. Modul GSM

Modul GSM ini digunakan sebagai notifikasi langsung kepada penanggung jawab ruang server apabila terjadi kebakaran berupa sms gateway [7].

4. Sensor suhu DHT11

Sensor suhu sebagai alat pendeteksi suhu. Modul ini menghubungkan Vcc/+ dengan 5v. GND/- dengan
GND dan out dengan pin0. Untuk pengiriman dan penerimaan data antara DHT11 arduino [8].

5. Buzzer

Buzzer dugunakan sebagai notifikasi terbentuknya suara apabila kedua sensor menerima inputan yang telah diroses pada mikrokontroler arduino uno.

6. LCD (Liquid Crystal Display)

LCD adalah perangkat yang berfungsi sebagai media tampilan dengan memanfaatkan Kristal cair sebagai objek penampil utama[9][10].

\section{B. Rangkaian Keseluruhan alat}

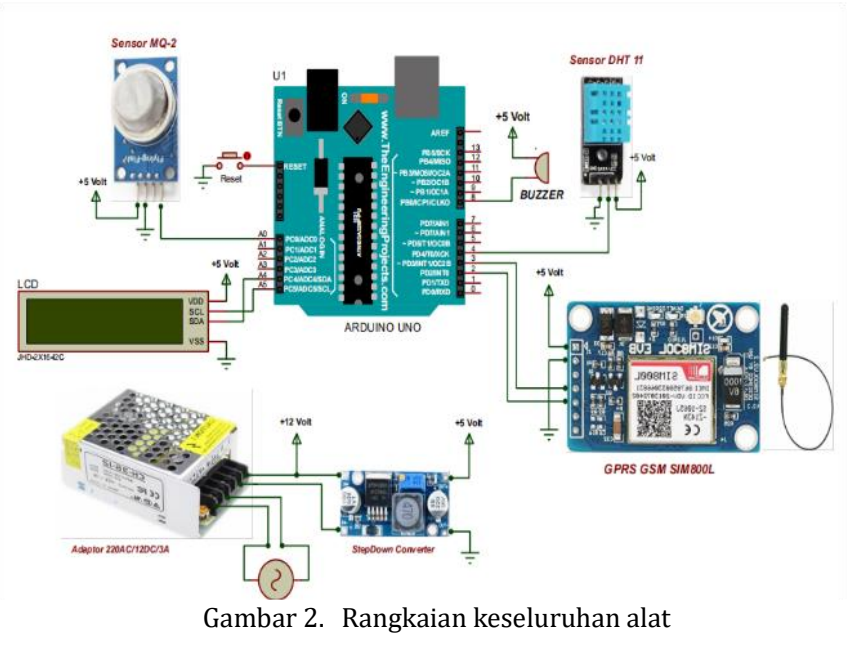

\section{Perancangan Mekanik Alat}

Perancangan mekanik merupakan suatu proses atau tahapan dalam pembuatan tugas akhir untuk dapat diuji secara nyata.

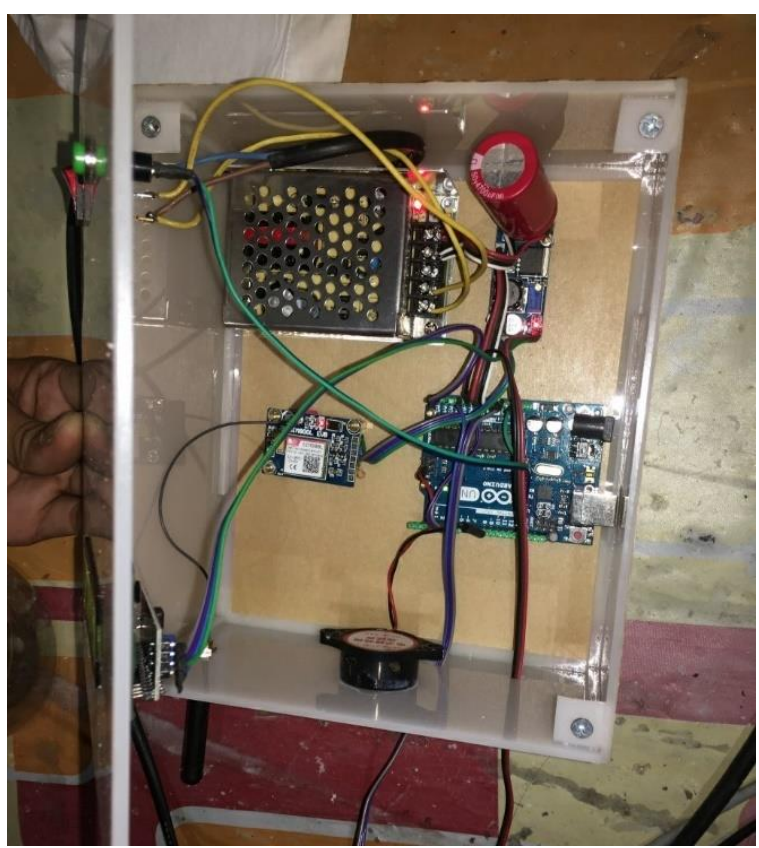

Gambar 3. Perancangan mekanik 


\section{HASIL DAN PEMBAHASAN}

Pada hasil dan pembahasan, akan dilakukan beberapa pengujian dan Analisa pada bagian input dan output. Pengujian ini bertujuan untuk mengetahui terhadap kinerja keberhasilan alat dalam pengujian nyata.

\section{A. Pengujian Sensor MQ2}

Pengujian ini dilakukan dengan menggunakan kertas yang dibakar sehingga mengeluarkan asap yang banyak, tujuannya adalah untuk mengetahui kadar dan konsentrasi gas dan asap oleh sensor MQ2 yang digunakan untuk mendeteksi karbon monoksida diruangan. Dalam pengujian sensor MQ2 ini diuji menggunakan korek api gas dengan mendekatkannya ke sensor MQ2 hasil pengujiannya terlihat pada table 1 berikut.

\begin{tabular}{|c|c|c|c|c|}
\hline \multicolumn{5}{|c|}{ TABEL I. PENGUJIAN SENSOR MQ2 } \\
NO & $\begin{array}{c}\text { Tegangan } \\
\text { Output }\end{array}$ & $\begin{array}{c}\text { Asap } \\
\text { Terdata } \\
\text { (ADC) }\end{array}$ & Buzzer & Keterangan \\
\hline 1 & $0.33 \mathrm{v}$ & 68.01 & Hidup & Bahaya \\
\hline 2 & $0.28 \mathrm{v}$ & 57.00 & Hidup & Waspada \\
\hline 3 & $0.13 \mathrm{v}$ & 26.00 & Mati & Normal \\
\hline 4 & $0.09 \mathrm{v}$ & 19.00 & Mati & Normal \\
\hline
\end{tabular}

Dari data table diatas dapat dilihat apabila tegangan $>$ 0.28 volt maka sensor mendeteksi adanya asap yang berlebihan.

\section{B. Pengujian Sensor DHT11}

Pengujian sensor DHT11 bertujuan untuk mengetahui kemampuan sensor dalam membaca suhu diruangan dan membandingkan dengan alat pembaca temperatur lainnya. Pengujian dengan cara memberi api pada sensor DHT11 jika ambang batas untuk suhu melebihi batas maka lampu indikator hidup, buzzer hidup, menampilkan lcd dan pompa air hidup serta mengirimkan notifikasi ke handphone melalui modul GSM [10][11].
TABEL II. PENGUJIAN SENSOR SUHU DHT11

\begin{tabular}{|c|c|c|c|c|}
\hline NO & Waktu & Suhu terdata $\left(\mathrm{C}^{0}\right)$ & Buzzer & Keterangan \\
\hline 1 & $\begin{array}{c}30 \\
\text { menit }\end{array}$ & $45^{\circ} \mathrm{C}$ & Hidup & Bahaya \\
\hline 2 & $\begin{array}{c}30 \\
\text { menit }\end{array}$ & $40^{\circ} \mathrm{C}$ & Hidup & Waspada \\
\hline 3 & $\begin{array}{c}30 \\
\text { menit }\end{array}$ & $38^{\circ} \mathrm{C}$ & Hidup & Waspada \\
\hline 4 & $\begin{array}{c}30 \\
\text { menit }\end{array}$ & $36^{\circ} \mathrm{C}$ & Mati & $\begin{array}{c}\text { Normal/Am } \\
\text { an }\end{array}$ \\
\hline
\end{tabular}

Dari hasil uji coba diatas dapat dijelaskan dari sensor DHT11 ini dengan memberi tegangan input 5 VDC. Maka sensor ini mampu mendeteksi suhu sesuai dengan pengaturan ambang batas pada $36^{\circ} \mathrm{C}$ dengan melihat hasilpengujian dari tabel diatas bahwa sensor DHT11 bekerja dengan baik ketika suhu melebihi ambang batas maka indicator lampu dan buzzer hidup dan mengirimkan notifikasi pada handphone melalui modul GSM.

\section{Pengujian LCD}

Pengujian LCD bertujuan untuk menampilkan data pada LCD, dan hasilnya diamati langsung pada layar LCD, dari hasil pengamatan LCD bisa menampilkan karakter dengan baik. Jumlah karakter yang ditampilkan sebanyak $16 \times 2$.

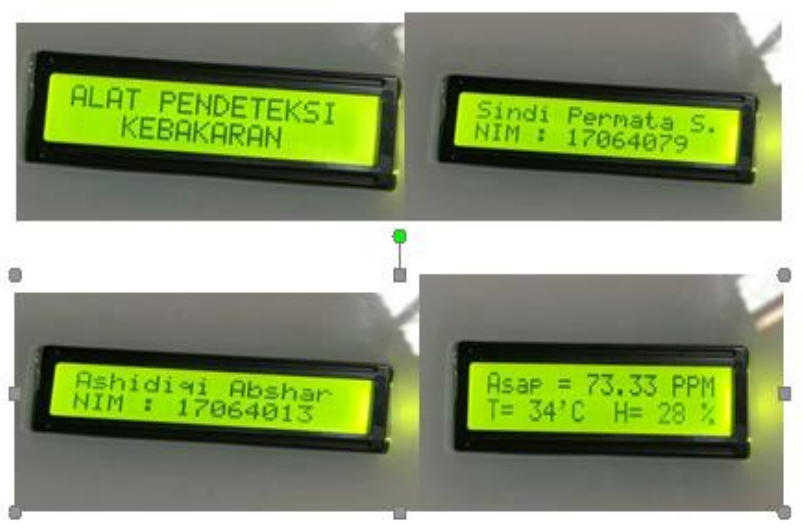

Gambar 4. Tampilan LCD

\section{Pengujian Modul GSM sim1800L}

Pengiriman data pada pengguna dilakukan dengan modul GSM SIM1800L yang terhubung ke arduino uno melalui pin RX dan TX. Modul ini bisa menerima data yang terbaca oleh arduino berdasarkan nilai sensor. Nilai 
sensor yang terbaca pada arduino uno akan dikirimkan oleh modul GSM SIM1800L kepada nomor handphone pengguna yang sudah terkoneksi pada SIM tersebut.

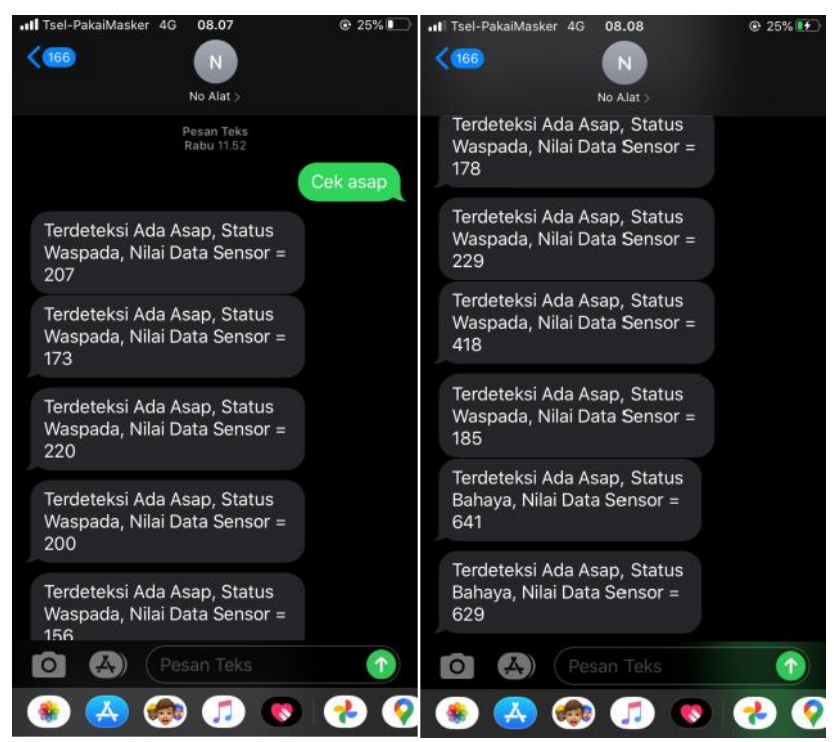

Gambar 5. Tampilan pengujian modul GSM sim1800L

\section{PenutuP}

Dari hasil pengujian dapat disimpulkan bahwa rangkaian mikrikontroller Arduino uno bekerja dengan baik sesuai program yang telah dibuat, pada saat terdeteksi asap kebakaran maka buzzer akan berbunyi dan LCD menampilkan tegangan dan kondisi asap kebakaran dan jika terjadi asap kebakaran hanya alarm peringatan yang aktif dan secara otomatis akan mengirimkan SMS peringatan bahwa terdeteksi adanya asap yang berlebihan.

\section{REFERENSI}

[1] H. Hamuda, "Alat Pendeteksi Kebakaran Mengunakan_Mik.” p. 72, 2015.

[2] Rosidah;., "Bab Ii Landasan Teori," J. Chem. Inf. Model., vol. 53, no. 9, pp. 8-24, 2018.

[3] J. Asmi and 0. Candra, "Prototype Solar Tracker Dua Sumbu Berbasis Microcontroller Arduino Nano dengan Sensor LDR," JTEV (Jurnal Tek. Elektro dan Vokasional), vol. 6, no. 2, p. 54, 2020, doi: 10.24036/jtev.v6i2.108504.

[4] Z. Buana, 0. Candra, and Elfizon, "Sistem Pemantauan Tanaman Sayur Dengan Media," vol. V, no. 1, pp. 74-80, 2019.

[5] 0. Candra, Z. Saputra, and Aswardi, "Sistem Pemanas Logam dengan Induction Heater Berbasis Atmega32," pp. 151-157, 2019.

[6] I. N. B. Perwira and W. Broto, "Pembuatan Alat Pendeteksi Api Dan Asap Berbasis Mikrokontroller Arduino Uno Dan Sensor Mq-2 Keluaran Sms Gateway," vol. VI, pp. SNF2017-CIP-31-SNF2017CIP-40, 2017, doi: 10.21009/03.snf2017.02.cip.05.

[7] D. Sasmoko and A. Mahendra, "Rancang Bangun Sistem Pendeteksi Kebakaran Berbasis Iot Dan Sms Gateway Menggunakan Arduino," Simetris J. Tek. Mesin, Elektro dan Ilmu Komput., vol. 8, no. 2, p. 469, 2017, doi: 10.24176/simet.v8i2.1316.

[8] S. Fuadi, O. Candra, U. N. Padang, J. Prof, and H. Air, "Prototype Alat Penyiram Tanaman Otomatis dengan Sensor Kelembaban dan Suhu Berbasis Arduino," vol. 1, no. 1, pp. 21-25, 2020.

[9] Dylan Trotsek, “済無No Title No Title," J. Chem. Inf. Model., vol. 110, no. 9, pp. 1689-1699, 2017.

[10] R. Anggriawan and O. Candra, "Rancang Bangun Pengaman Pintu Ruang Kuliah Menggunakan Sensor Fingerfrint Berbasis Arduino Mega2560," vol. 6, no. 1, pp. 25-34, 2020.

[11] A. Widodo and O. Candra, "Kontrol Sepeda Motor Menggunakan Andorid," vol. 1, no. 2, pp. 63-68, 2020.

\section{Biodata Penulis}

Sindi Permata Sari, lahir di Koto Berapak, 07 juni 1998. Telah menyelesaikan studi di Teknik elektro UNP dan mendapat gelar A.Md Teknik di FT UNP.

Oriza Candra, S.T, M.T, Lahir di Padang, Sarjana Teknik Elektro UNJANI Bandung. Tahun 2005 memperoleh gelar Magister Teknik di FT UGM. Dari 1999 sampai sekarang bertugas sebagai Dosen Tetap pada Jurusan Teknik Elektro FTUNP.

Jhefri Asmi, lahir di Balai Tangah, 10 Juli 1998. Sedang menempuh jenjang sarjana pada Program Studi Teknik Elektro Industri di jurusan Teknik Elektro FT UNP. 